Tuberc Respir Dis 2012;73:122-126

Copyright(C)2012. The Korean Academy of Tuberculosis and Respiratory Diseases. All rights reserved.

\title{
Plastic Bronchitis in an Adult with Asthma
}

Eun Jin Kim, M.D., Ph.D. ${ }^{1}$, Jung Eun Park, M.D. ${ }^{1}$, Dong Hoon Kim, M.D., Ph.D. ${ }^{2}$, Jaehee Lee, M.D., Ph.D. ${ }^{3}$ Departments of Internal Medicine and ${ }^{2}$ Pathology, CHA Gumi Medical Center, CHA University School of Medicine, Gumi, ${ }^{3}$ Department of Internal Medicine, Kyungpook National University School of Medicine, Daegu, Korea

Plastic bronchitis is a rare disease characterized by marked airway obstruction, via the formation of large gelatinous or rigid airway cast. In Korea, there were a few case reports with plastic bronchitis not in adults, but in children. So we report a case of an adult who was diagnosed as plastic bronchitis with eosinophilic casts, with no history of atopic and cardiac disease.

Key Words: Bronchitis; Etiology; Asthma; Adult

\section{Introduction}

Plastic bronchitis is a rare disease characterized by the formation of large gelatinous or rigid airway cast. These casts are large and more cohesive than those seen in ordinary mucus plugging ${ }^{1,2}$. Bronchial casts are generally associated with cyanotic congenital heart disease $^{2}$, acute chest syndrome associated with sickle cell disease $^{3}$ and diffuse bronchial hypersecretory disorders, such as asthma, cystic fibrosis, allergic bronchopulmonary aspergillosis, bacterial or viral respiratory infection $^{3,4}$. And these are also reported to be present in pericardial effusion and heart failure ${ }^{4,5}$.

In Korea, there were a few case reports with plastic bronchitis not in adults but in children ${ }^{5-7}$. So we for the first time report an adult who was diagnosed as plastic bronchitis with eosinophilic casts, with no history of atopic and cardiac disease in Korea.

Address for correspondence: Eun Jin Kim, M.D., Ph.D. Department of Internal Medicine, CHA Gumi Medical Center, CHA University School of Medicine, 855, Hyeonggokdong, Gumi 730-728, Korea

Phone: 82-54-450-9550, Fax: 82-54-450-9798

E-mail: kejean@naver.com

Received: Mar. 6, 2012

Revised: Apr. 2, 2012

Accepted: Apr. 25, 2012

(a) It is identical to the Creative Commons Attribution Non-Commercial License (http://creativecommons. org/licenses/by-nc/3.0/).

\section{Case Report}

A 27-year-old female visited our hospital complaining of worsening cough, sputum and rhinorrhea for a week, when she was in 34 weeks of pregnancy. She had neither any past medical history nor allergy history. Her vital sign and lung sound was normal. Laboratory studies revealed a white blood cell count of $13,500 / \mu \mathrm{L}$ (polymorphonuclear cells 66.6\%, lymphocytes $17.7 \%$, and eosinophils $6.6 \%$ ), a hemoglobin of $11.8 \mathrm{~g} / \mathrm{dL}$ and a platelet count of $224,000 / \mu \mathrm{L}$. A chest radiograph was within normal limits (Figure 1A). She was diagnosed with acute bronchitis and was taken symptomatic drugs (antitussive and antihistamine drugs).

Two days later, she visited again and her lung sound showed up wheezing in both lower lung fields. We did the pulmonary function test (PFT) with bronchodilator response. That showed the forced vital capacity (FVC) $3.32 \mathrm{~L}$ (86\% of predicted portends), the forced expiratory volume in one second $\left(\mathrm{FEV}_{1}\right) 2.74 \mathrm{~L}$ (83\% of predicted portends) and the $\mathrm{FEV}_{1} / \mathrm{FVC} 82 \%$. When she inhaled bronchodilator, $\mathrm{FEV}_{1}$ increased only $9 \%$. She could not be diagnosed with asthma. The average forced expiratory flow rate over the middle 50\% of the FVC $\left(\mathrm{FEF}_{25-75}\right)$ reflects peripheral airway function, her $\mathrm{FEF}_{25-75}$ was $63 \%$ and $86 \%$ before and after using bronchodilator, respectively. $\mathrm{FEF}_{25-75}$ change between before and after bronchodilator use reached 35\%. It could not 

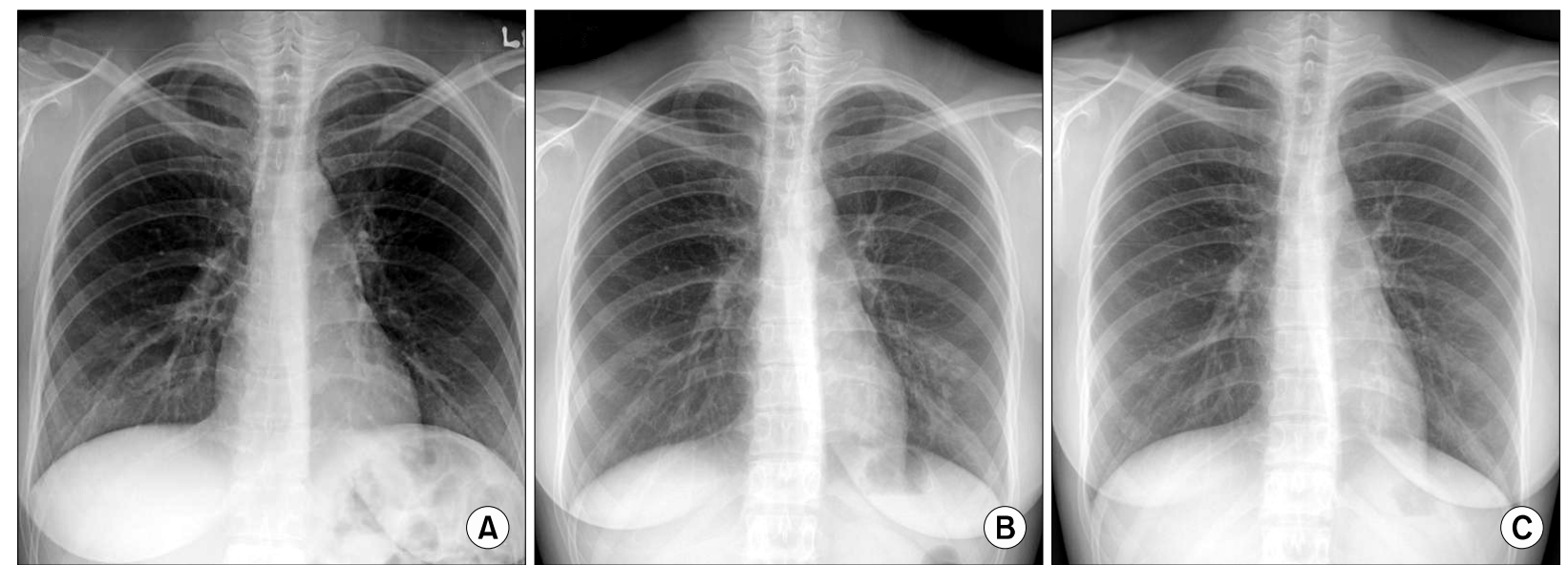

Figure 1. (A) Initial chest X-ray shows no definite abnormalities. (B) After 2 months, chest X-ray shows infiltration at the left lower lung field. (C) After bronchoscopic removal of bronchial casts, chest X-ray shows a dramatically improvement of infiltration at the left lower lung fields.
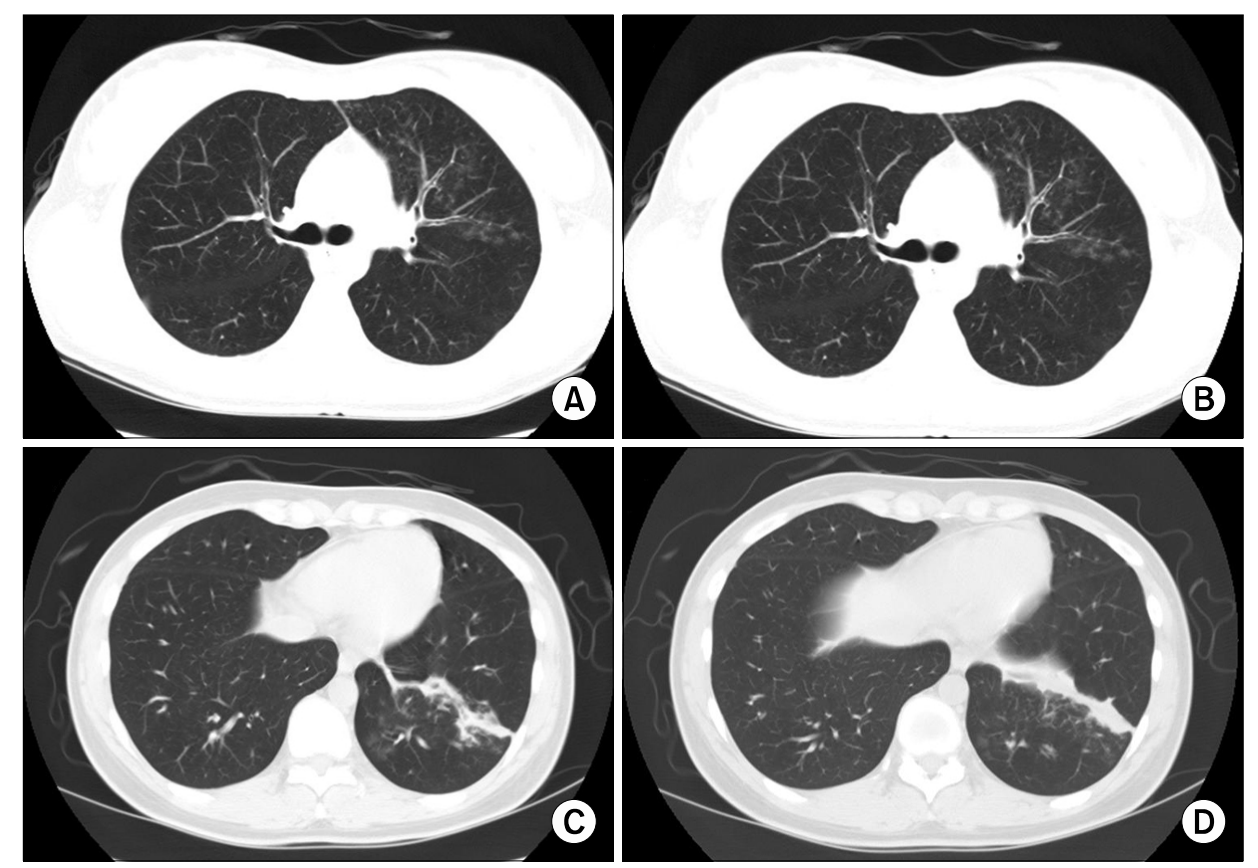

Figure 2. Chest computed tomography shows multiple nodular infiltration at left upper lobe (A, B) and consolidation at left lower lobe $(C, D)$, suggesting tuberculosis.

diagnose her as having asthma, but meant that she got peripheral airway obstructive dysfunction. On the grounds of wheezy lung sound, we diagnosed her as asthma and treated her with a budesonide turbuhaler, an antibiotic (clarithromycin), montelukast and antihistamine even though PFT did not meant asthma at that time. After this treatment, she did not come again in our hospital.

Two months later, she referred to our hospital be- cause of left upper and lower lobe consolidation at chest high resolution computed tomography (HRCT) in the other hospital (Figure 2). She complained of severe cough, thick purulent sputum and rhinorrhea, but did not have fever. She lost weight about $7 \mathrm{~kg}$ after delivery. Her lung sound was normal without wheezing. She was admitted to our hospital, and got blood tests. In laboratory tests, there were a white blood cell count of $8,300 / \mu \mathrm{L}$ (polymorphonuclear cells $40.1 \%$, eosino- 

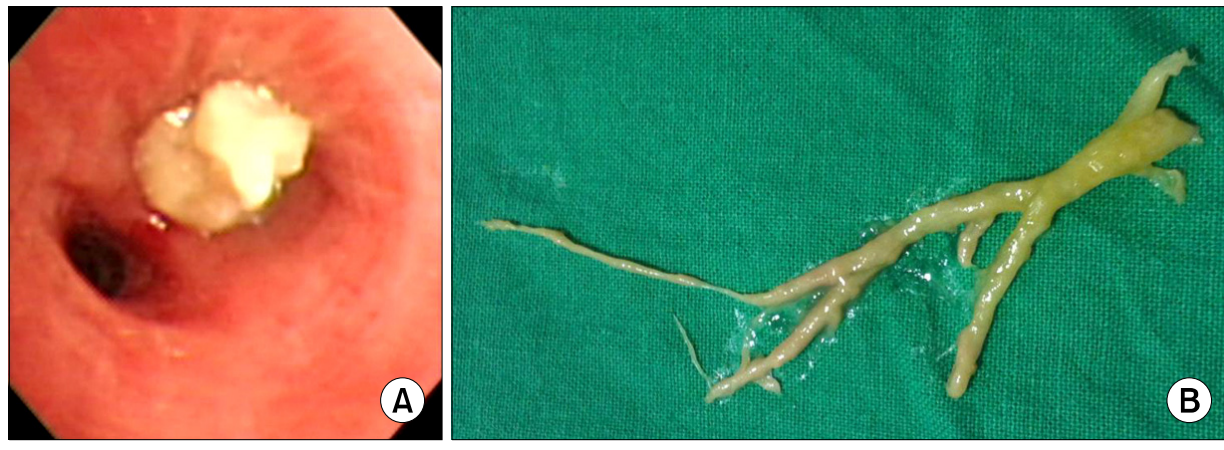

Figure 3. Bronchoscopic exam shows a hard purulent mass-like secretion at left lower lobe basal segment bronchus (A). Bronchoscopic removal of that mass reveals a large cast along bronchial tree (B).

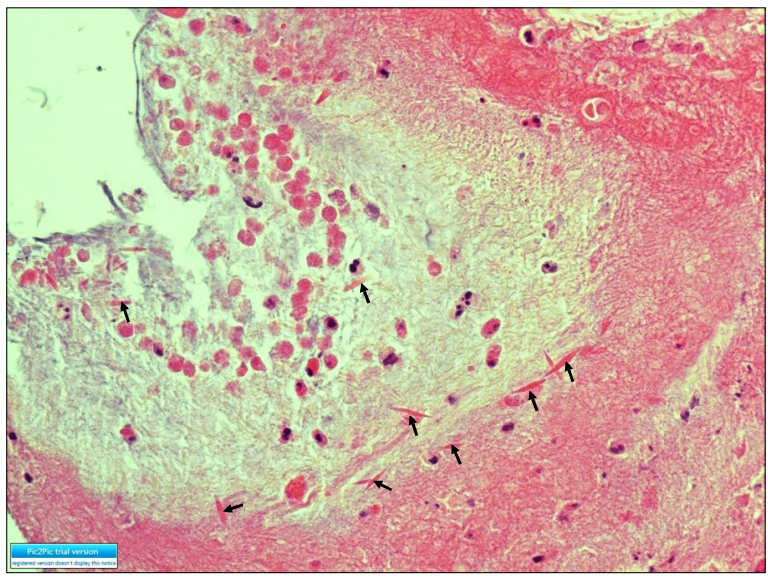

Figure 4. Biopsy specimen of mass-like secretion shows mucous plug, containing necrotic epithelial cells, some eosinophils and Charcot-Leyden crystals (arrows) (H\&E stain, $\times 400)$.

phils $14.6 \%$ ), a hemoglobin of $13.3 \mathrm{~g} / \mathrm{dL}$ and a platelet count of $516,000 / \mu \mathrm{L}$. The C-reactive protein level was $0.51 \mathrm{mg} / \mathrm{dL}$, urine pneumococcal antigen test was positive, and procalcitonin was $<0.05 \mathrm{ng} / \mathrm{mL}$. Electrolytes, liver and renal function test were in the normal range. A chest radiograph showed infiltration at left lower lung field (Figure 1B) and a chest HRCT scan showed consolidation at left lower lobe and nodular infiltration at left upper lobe, suggesting tuberculosis (Figure 2). An electrocardiogram and echocardiography ware normal. Sputum smear and culture for routine bacteria, fungi and mycobacteria were negative. Her MAST allergen test was negative and total IgE level was within normal limit.

We treated her with antibiotics against Streptococcus pneumoniae and bronchodilator. Because her long du- ration of respiratory symptoms and chest images suggested tuberculosis, we had to exclude tuberculosis or atypical pulmonary infection, so performed bronchoscopy. In bronchoscopy, there was a hard purulent mass-like secretion at left lower lobe basal segment bronchus (Figure 3A), we suctioned and retracted a large cast along bronchial tree (Figure 3B). After removal of a bronchial cast, there was no bronchial obstructive lesion.

In biopsy specimen, there was consistent with mucous plug, containing necrotic epithelial cells, some eosinophils and Charcot-Leyden crystals (Figure 4).

On diagnosed with plastic bronchitis, we treated her with a budesonide/formoterol turbuhaler, steroid, a mucolytic agent and antibiotics. After removal of bronchial casts, her symptom got better dramatically, and her chest radiograph showed improvement of infiltration in left lower lung field (Figure 1C), so she was discharged.

After 3 months of discharge, she had the methacholine bronchial challenge test that result was positive for asthma.

\section{Discussion}

Plastic bronchitis has been called by different names over the years. It has been referred to as Hoffman's bronchitis, cast bronchitis, pseudomembranous bronchitis or fibrinous bronchitis ${ }^{2,8}$. Seear et al. ${ }^{9}$ classified it into two well-defined groups: type 1 (inflammatory), consisting of casts composed mainly of fibrin with a dense eosinophilic inflammatory infiltrate; and type 2 (acellular), consisting of casts composed mainly of mucin with little or no cellular infiltrate and occurring in children with 
congenital cyanotic heart disease.

The prevalence of plastic bronchitis is unknown, but rare. Many patients go undiagnosed. Plastic bronchitis can occur at any age, but the majority of published reports involve pediatric patients ${ }^{8}$. Only few cases have been described among adults ${ }^{2,8,10-12}$. These cases were associated with acellular cast such as idiopathic ${ }^{8,10,11}$ or lymphatic abnormalities ${ }^{2}$ as well as inflammatory conditions $^{12}$ such as pneumonia, bronchiectasis and tuberculosis.

The clinical presentation has productive cough, dyspnea, pleuritic chest pain, fever and wheezing. Radiographic evaluation reveals the site of the bronchial cast impaction, demonstrating atelectasis or infiltrates. Hyperinflation is often evident on the contralateral side ${ }^{6}$. The CT scan allows visualization of impacted casts within the major airways. The diagnosis is usually confirmed by bronchoscopy, demonstrating airway obstruction from bronchial casts ${ }^{6,8}$.

Asthma and atopic disease are the next most common reported association with plastic bronchitis after congenital heart disease. Madsen et al. ${ }^{2}$ reviewed published reports of plastic bronchitis from 1965 to 2005. According to Madsen et al. ${ }^{2}$, of the 22 reported patients with eosinophilic casts, 12 cases defined atopic or asthmatic condition and one was an adult case. The mean age was 6 years (range, 13 months $\sim 40$ years), slight female predominance and 3 deaths were reported ${ }^{2}$. The mortality has been estimated at 6 50\% for 'inflammatory' casts $^{2,3,9}$.

The treatment of plastic bronchitis is represented by endoscopic extraction of the casts. Complete extraction is always a very delicate procedure that often needs fragmentation and several successive bronchoscopy ${ }^{13}$. Treatment has historically included bronchodilators, inhaled and oral corticosteroids, mucolytic agents, airway clearance therapy and antibiotics. Other therapeutic options have included inhaled heparin, urokinase, tissue plasminogen activator, dornase alfa and oral macrolide antibiotics as mucoregulatory therapy ${ }^{2}$.

In patients with asthma or atopic disease and type I cast, therapy should be directed toward treating under- lying inflammation. Oral and inhaled corticosteroids, low-dose long-term 14- and 15-member macrolide antibiotics and culture-directed therapy of infection have been reported to help ${ }^{2}$. The 14- and 15-member macrolide antibiotics are known to be both immunomodulatory and mucoregulatory drugs ${ }^{2,7,14}$. Anti-fibrin therapies can be used if fibrin is present ${ }^{2}$.

Our patient had asthma that was not controlled because of irregular medication. She showed abnormal findings at her chest images, suggesting tuberculosis or atypical pneumonia. In bronchoscopy, that was revealed plastic bronchitis, pathologically type I inflammatory cast. After bronchoscopic removal of a large cast, her respiratory symptom was dramatically reduced. And her respiratory symptom was stable after using bronchodilator, inhaled steroid and antibiotics.

This is a rare case of plastic bronchitis that occurred in an adult with asthma.

\section{References}

1. Liston SL, Porto D, Siegel LG. Plastic bronchitis. Laryngoscope 1986;96:1347-51.

2. Madsen P, Shah SA, Rubin BK. Plastic bronchitis: new insights and a classification scheme. Paediatr Respir Rev 2005;6:292-300.

3. Brogan TV, Finn LS, Pyskaty DJ Jr, Redding GJ, Ricker $\mathrm{D}$, Inglis A, et al. Plastic bronchitis in children: a case series and review of the medical literature. Pediatr Pulmonol 2002;34:482-7.

4. Bowen A, Oudjhane K, Odagiri K, Liston SL, Cumming WA, Oh KS. Plastic bronchitis: large, branching, mucoid bronchial casts in children. AJR Am J Roentgenol 1985;144:371-5.

5. Park JY, Elshami AA, Kang DS, Jung TH. Plastic bronchitis. Eur Respir J 1996;9:612-4.

6. Cho YK, Oh SM, Choi WY, Song ES, Han DK, Kim YO, et al. Fatal plastic bronchitis with eosinophilic casts in a previously healthy child. Korean J Pediatr 2009;52: 1048-52.

7. Kim YH, Choi HJ, Kim JO, Hyun MC. Plastic bronchitis in children: 2 cases. Korean J Pediatr 2009;52:832-6.

8. Eberlein MH, Drummond MB, Haponik EF. Plastic bronchitis: a management challenge. Am J Med Sci 2008;335:163-9.

9. Seear M, Hui H, Magee F, Bohn D, Cutz E. Bronchial 
EJ Kim et al: Plastic bronchitis in an adult with asthma

casts in children: a proposed classification based on nine cases and a review of the literature. Am J Respir Crit Care Med 1997;155:364-70.

10. Quysner A, Surani S, Roberts D. Plastic bronchitis. West J Emerg Med 2011;12:118-9.

11. Jett JR, Tazelaar HD, Keim LW, Ingrassia TS 3rd. Plastic bronchitis: an old disease revisited. Mayo Clin Proc 1991;66:305-11.

12. Wang G, Wang YJ, Luo FM, Wang L, Jiang LL, Mao B. Effective use of corticosteroids in treatment of plastic bronchitis with hemoptysis in Chinese adults. Acta Pharmacol Sin 2006;27:1206-12.

13. Noizet O, Leclerc F, Leteurtre S, Brichet A, Pouessel G, Dorkenoo A, et al. Plastic bronchitis mimicking foreign body aspiration that needs a specific diagnostic procedure. Intensive Care Med 2003;29:329-31.

14. Rubin BK, Henke MO. Immunomodulatory activity and effectiveness of macrolides in chronic airway disease. Chest 2004;125(2 Suppl):70S-8S. 